\title{
Et tu, Brute? Surprising Actions and Their Market Reaction
}

\author{
Jeffrey E. Baker \\ United States Army War College
}

\begin{abstract}
We contribute to competitive dynamics research by using an Event System Theory lens to explain how surprising competitive actions explain market value for both the actors and the actee firms. We propose that surprising competitive actions produce a negative impact on a surprised firm while the firm conducting the action receives a positive impact to their abnormal returns. Conducting an event study over a five-year period, we found that the impact of surprising actions is greater than the impact of nonsurprising actions. Our findings also provide justification for firms to invest in competitive intelligence functions for environmental scanning.
\end{abstract}

Keywords: Competitive Dynamics, Surprise, Event Systems Theory

\section{INTRODUCTION}

There is an increasing interest in how competitive actions, defined as externally directed, specific, and observable competitive moves, impact firm performance (Chen \& Miller, 2015; Chen \& Miller, 2012; Connelly, Tihanyi, Ketchen, Carnes, \& Ferrier, 2017). In the strategic competitive behavior stream of research, scholars have examined how a firm's pattern of competitive actions influenced firms' stock market performance and found that short-sellers and long-buyers react differently to firms' competitive action (Hughes-Morgan, Ferrier, \& Morgan, 2018). Hughes-Morgan \& Ferrier (2017) found that firms that are facing increased Wall Street pressure conduct a higher number of competitive actions as well as actions that diverge from industry norms. Andrevski, Brass, \& Ferrier (2016) studied alliance portfolio configurations and competitive action frequency and suggest that structural holes, R\&D alliance scope, and equity alliances play critical roles in the action development process.

However, the role of surprising actions in the field of competitive dynamics is an understudied area for firms attempting to gain a competitive advantage. This neglect is noteworthy as surprises are an increasing aspect of organizational life (Bechky \& Okhuysen, 2011; Hillmann, Duchek, Meyr, \& Guenther, 2018; Patriotta \& Gruber, 2015). The impact of a surprise on a firm can result in organizational catastrophes (Shrivastava, 1992; Weick, 1993), faltering reputations (Fombrun \& Rindova, 2000), or weakened competitive positions (Provan \& Skinner, 1989).

The purpose of this paper is to contribute to the competitive dynamics and surprise literatures by establishing a theoretical link between a surprising action by a firm and the abnormal returns of those firms. Establishing this link is critical since not all managers and professionals are convinced that anticipating potential surprises by competitors is worth the costs (Montgomery, Moore, \& Urbany, 2005; Steenkamp, Nijs, Hanssens, \& Dekimpe, 2005; Wright, Eid, \& Fleisher, 2009) or particularly effective 
(Powell \& Allgaier, 1998). This view is surprising as environmental scanning has long been considered fundamental to strategy (Nag, Hambrick, \& Chen, 2007). The lack of agreement on the resources that should be dedicated to anticipating surprise as well as a lack of scholarly attention on the immediate financial impacts of surprise on a firm motivated our research question. In the context of competitor dynamics, how do surprising actions by a competitor impact the abnormal return of the actor and actee firms?

We approach our research question in the following way. Adopting an event system theory lens (Morgeson, Mitchell, \& Liu, 2015), we focused our theoretical and empirical attention at the firm level on a specific type of event, surprising competitive actions. We theorize that as firms conduct surprising competitive actions, the firms that conduct the action will have an immediate positive financial impact and those that get surprised by an action from a competitor will have an immediate negative financial impact, as defined as the abnormal return.

Our approach is also consistent with the competitive dynamic's literature. The primary reason for firms in a competitive setting to conduct actions is to enhance a firms' relative competitive position (Chen \& Miller, 2012; Más-Ruiz, Nicolau-Gonzálbez, \& Ruiz-Moreno, 2005; Smith, Grimm, Wally, \& Young, 1997). Previous scholars have theorized that competitive actions impact firms abnormal returns (Goins \& Gruca, 2008; Hughes-Morgan et al., 2018; Lee, Smith, Grimm, \& Schomburg, 2000), and decisionmakers are making decisions based on short-term market performance (Ferrier \& Lee, 2002).

We used a dataset of 179 published articles collected from the Factiva that described a competitive action resulted in a sample of 403 firms. These 403 firms included 185 firms that initiated the action (actors) and 218 firms that were the target of those actions (actees). We used the event study methodology and found that surprising actions impact abnormal returns. Figure 1 illustrates our model.

\section{FIGURE 1}

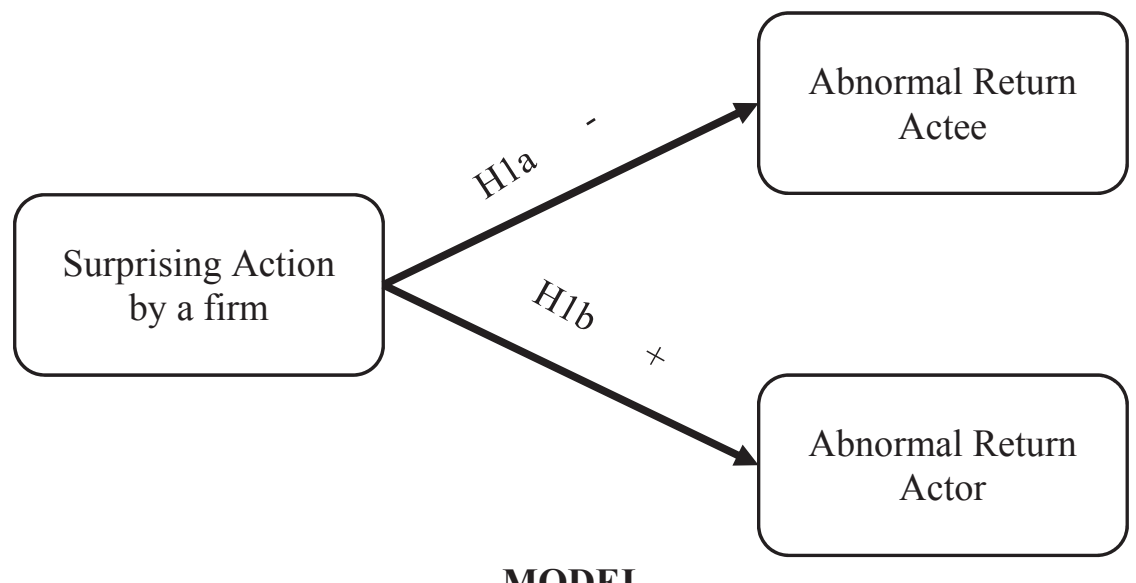

MODEL

We contribute to research on competitive dynamics by introducing Event System Theory to develop a deeper understanding of the relationship between the characteristics of a competitive action and firm performance. We develop theory as to how surprising actions impact the abnormal returns of the firms. We provide a novel lens to view surprise in the context of the competitive dynamics by incorporating elements of the Event System Theory for firms conducting surprising competitive actions. Demonstrating the financial impact that surprise has on a firm provides evidence for scholars and practitioners to articulate the justification for dedicating finite resources to both generating and anticipating surprising actions. If managers better understand the potential costs/benefits associated with a surprise, then they can be more confident in their decisions to allocate resources to mitigating the effect of a surprise, identifying and anticipating potential surprises, or launching surprising attacks on competitors. 


\section{THEORY AND HYPOTHESES}

\section{Competitive Actions}

Competitive Dynamics is the study of rivalry among firms, the specific actions and reactions that firms take, the motivations and outcomes of the actions, as well as their strategic and organizational contexts (Baum \& Korn, 1996; Miller \& Chen, 2013). It is rooted in the Austrian school of economics which states that competition is a dynamic process where firms take actions to gain an advantage over their rivals (Jacobson, 1992; Kirzner, 1973; Schumpeter, 1934). The primary motivation for a firm in a competitive setting to conduct actions, defined as externally directed, specific, and observable competitive moves, is to enhance a firms' relative competitive position (Chen \& Miller, 2012; Más-Ruiz et al., 2005; Smith et al., 1997).

Scholars have studied the impact of competitive actions on the firms relative competitive position using a variety of measures for firm performance such as market share gain (Andrevski, Richard, Shaw, \& Ferrier, 2014), return on sales (Derfus, Maggitti, Grimm, \& Smith, 2008; Young, Smith, \& Grimm, 1996), return on assets (Stambaugh, Lumpkin, Brigham, \& Cogliser, 2009; Young et al., 1996), and abnormal returns (Ferrier \& Lee, 2002; Goins \& Gruca, 2008; Margaret; Hughes-Morgan et al., 2018; McNamara, Haleblian, \& Dykes, 2008; Zantout \& Chaganti, 1996). Abnormal returns are a useful measure of firm performance as managers are increasingly using short-term market performance to make decisions (Ferrier \& Lee, 2002).

Scholars maintain that these competitive actions vary across resources, complexity, and time (Andrevski et al., 2013). These actions can range from strategic actions that consume significant resources and are difficult to implement or tactical actions, such as price changes or marketing campaigns, which are relatively simple to implement (Andrevski et al., 2016; Miller \& Chen, 1994). Firms conduct these competitive actions to create a temporary advantage or to erode their rivals' market positions (Andrevski et al., 2014; Young et al., 1996).

\section{Event System Theory and Surprise}

Our theoretical model draws from Morgeson et al.'s (2015) Event System Theory (EST). One of the primary motivations of EST is to provide an understanding of what makes an event impactful to an organization. In EST, events are defined as discrete, discontinuous happenings that are not part of the routine organizational environment. EST suggests that events become salient when they are novel, disruptive, and critical. These events change or create new behaviors, features, and events. The impact of an event can extend over time as events vary in duration, timing, or as event strength evolves.

Although EST describes three components of an event, this research will primary focus on one area of the theory, novelty, as previous scholars have indicated that novelty and surprise are closely related (Barto, Mirolli, \& Baldassarre, 2013; Marsland, 2002; Morgeson, 2005; Morgeson et al., 2015; Ranganath \& Rainer, 2003). Focusing on only one aspect of EST is consistent with the theory as the theory suggests that the three components of EST can function independently (Morgeson et al., 2015).

In EST, novelty refers to when an event represents a new or unexpected phenomenon such as a competing company designing a new product (Morgeson et al., 2015). The more novel the event, the larger the impact on organizations as those organizations typically are not prepared with routines or procedures to effectively respond to the novel event (Burt, 2007; Feldman \& Pentland, 2003; Morgeson et al., 2015).

\section{Surprise and Abnormal Returns}

Surprise, as defined by Cunha, Clegg, \& Kamoche (2006), is "any event that happens unexpectedly or any expected event that takes an unexpected turn." Further, the authors suggest that to be surprised is not a lack of surety about a phenomenon but a sudden or unexpected meeting with a phenomenon not previously considered. It is to be taken completely "unawares and to feel a sense of wonder, astonishment, or amazement at something unanticipated." We define surprise as a break in expectations 
that come from situations that are not anticipated (Cunha et al., 2006) and draws attention away from the standard progression of work (Bechky \& Okhuysen, 2011).

Previous researchers have described surprise as a distinct emotional response to events and categorized surprise as positive (Allen, Varga, \& Strathern, 2010; Fontaine, Scherer, Roesch, \& Ellsworth, 2007; Kaplan, 2012; Valenzuela, Mellers, \& Strebel, 2010), others have stated that surprise is neutral (Russel, 1980). However, several independent lines of research in social psychology show that inconsistencies, disruption, and lack of structure are categorized as negative (Elliot \& Devine, 1994; Kay, Whitson, Gaucher, \& Galinsky, 2009; Proulx, Inzlicht, \& Harmon-Jones, 2012; Rutjens, Van Harreveld, Van Der Pligt, Kreemers, \& Noordewier, 2013; Topolinski \& Strack, 2015). After a comprehensive review of the literature, Topolinski \& Strack (2015) assert that surprise elicits an immediate negative affective state, and these negative affective states can influence expectations (Valenzuela et al., 2010).

The mechanism that explains the abnormal returns is market expectations. Expectation reflects beliefs of prior information about what is possible or probable in the future (Barney, 1986; Manski, 2004; Muth, 1961; Summerfield \& Egner, 2009). When a firm is surprised, it is subject to the expectation that it has lost control (Cornelissen, 2012; Cunha et al., 2006; Poppo \& Schepker, 2012), is poorly managed (Bundy, Pfarrer, Short, \& Coombs, 2017; Cunha et al., 2006; Neugarten, 2006; Pearson \& Clair, 1998) or likely to be at a competitive disadvantage (Ferrier \& Lee, 2002; Kasznik \& Lev, 1995). The market compares these expectations about the firm with its knowledge of the norms, values and strategic environment of the organizational field to assess the value of a firms stock price (Chauvin \& Guthrie, 1994; Goins \& Gruca, 2008; Vergin \& Qoronfleh, 1998).

Scholars theorize that firms conduct competitive actions to gain an advantage (Chen \& Miller, 1994; Ferrier \& Lee, 2002). As firms launch a surprising competitive action, the market expectation is that they caught the firm unaware and unprepared and obtained an advantage. As EST suggests that a novel event has a strong impact on organizations (Morgeson et al., 2015), we theorize that the firm launching the action will experience a positive abnormal return and the surprised firm will have a negative abnormal return. In sum, as firms conduct actions that surprise their competition, the market's expectation is that surprising action leads to an advantage for the acting firm and a disadvantage for the surprised firm. This expectation leads to a negative impact on the returns of the surprised firm and a positive impact on the returns of the firm that launched the attack.

H1a: A surprise as a result of a competitor's action will have a negative impact on a firm's abnormal return.

H1b: A surprising action on a competitor will have a positive impact on the acting firm's abnormal return.

As scholars have theorized that firms conduct actions in order to gain a competitive advantage (Chen \& Miller, 1994; Ferrier \& Lee, 2002), it is critical to distinguish between a surprising action and a nonsurprising action as the abnormal return could result from either the action or the surprising component to the action.

EST suggests that events become more impactful the greater the perceived novelty of the event is to an organization as those organizations are usually not prepared to effectively respond to the novel event (Morgeson et al., 2015). As non-surprising actions most likely generate from a set of competitive actions that have been a part of a competitor's competitive action repertoire (Ferrier \& Lee, 2002), firms most likely have developed actions and process to deal with the routine event (Feldman \& Pentland, 2003).

Since EST suggests that events become more impactful the greater the novelty (Morgeson et al., 2015), we hypothesize that firms conducting surprising actions will have greater positive abnormal returns than firms conducting non-surprising actions. In addition, firms that are surprised by competitive actions will have greater, negative abnormal returns than firms that are not surprised by competitive actions. 
H2a. Firms conducting surprising competitive actions have greater, positive abnormal returns than firms conducting non-surprising competitive actions.

$\boldsymbol{H} \mathbf{2 b}$. Firms that are surprised by competitive actions with have greater, negative abnormal returns than firms that are not surprised by competitive actions.

\section{METHODS}

\section{Data and Sample}

We searched the full-text articles from the Wall Street Journal and Wall Street Journal Online using the Factiva database to collect a sample of articles that exhibited surprising and non-surprising competitive actions. Following prior research, we conducted a structured content analysis of news article found in Factiva (Andrevski et al., 2013; Margaret; Hughes-Morgan et al., 2018; Margaret HughesMorgan \& Ferrier, 2017). The keyword search included variations of surprise, unexpected, astonishment, amazement, wonder, disbelief, and shock, as well as the keywords previously used by scholars to search for competitive actions (Ferrier \& Lee, 2002; Margaret Hughes-Morgan \& Ferrier, 2017). See Table 1. We read the full-text articles that contained these keywords and included articles in the sample that included surprising and non-surprising actions.

We excluded all articles in which the only surprise sentiment came from earnings announcements as this area is already a rich stream of research and it is beyond the scope of this paper. In addition, we excluded all articles where the surprise was explicit on outcomes instead of actions. For example, "Ford's compact SUV, the EcoSport, was launched last year and has been a surprise hit" (Choudhury \& Bennett, 2014). Since the launching of the EcoSport was not characterized as a surprise, but it's later success was, this article was not included in the sample. Surprises generated from outside entities that impacted an entire industry were not included in the sample. For example, Rapoport (2016), reported that the IRS issued a surprise ruling that "fines and penalties paid to the securities industry's self-regulatory organization shouldn't be considered tax-deductible, a stance that could cost financial firms that settle matters with the regulator."

TABLE 1

\section{KEY WORDS USED}

Concept

\begin{tabular}{|l|l|c|}
\hline Surprise & $\begin{array}{l}\text { Surprise, Unexpected, } \\
\text { Astonishment, Amazement, } \\
\text { Wonder, Disbelief, and Shock }\end{array}$ & 179 \\
\hline Pricing Actions & Price, Rate and Discount rebate & 6 \\
\hline Product Actions & $\begin{array}{l}\text { Introduce, Launch, Unveil, Rolls } \\
\text { out (with Product or Service) }\end{array}$ & 68 \\
\hline Capacity Actions & $\begin{array}{l}\text { Raises, Boost, Increases (with } \\
\text { Capacity or Output) }\end{array}$ & 14 \\
\hline Service Actions & $\begin{array}{l}\text { Service, Warrantee, Guarantee, } \\
\text { and Financing }\end{array}$ & 9 \\
\hline Signaling Actions & $\begin{array}{l}\text { Vows, Promises, Says, Seeks, } \\
\text { and Aims }\end{array}$ & 8 \\
\hline Marketing Actions & $\begin{array}{l}\text { Ads, Spot, Promote, Distribute, } \\
\text { and Campaign }\end{array}$ & 8 \\
\hline
\end{tabular}

In some instances, the article reported a surprise that happened in the past. For example, one of the articles reported that "Microsoft introduced the Surface tablet line last year, a surprise move into 
hardware" (Clark, 2013). In these cases, we researched the date that the action occurred and included that date as the event date, not the date of the article.

The search covered a period of five years from 2012 to 2017 resulting in 14,836 articles. We collected performance and control variable data from the Wharton Research Data Services' Compustat-Capital IQ function.

This method resulted in 240 articles with 526 firms that met the criteria outlined in the preceding section. Next, we checked to ensure that the firms did not have other events on the same date that could impact the financial data which further reduced the sample by 61 articles and 123 firms. This method resulted in 179 articles out of 14,836 (1.21\%) with 403 firms, consisting of 128 surprising action articles and 51 non-surprising action articles. See Table 2 for a distribution of the articles of the five-year period.

TABLE 2

DISTRIBUTION OF THE ARTICLES AND FIRMS BY YEAR

\begin{tabular}{|c|c|c|c|c|}
\hline Year & Articles & $\%$ & Firms & $\%$ \\
\hline 2013 & 44 & $24.6 \%$ & 98 & $24.3 \%$ \\
\hline 2014 & 44 & $24.6 \%$ & 99 & $24.6 \%$ \\
\hline 2015 & 37 & $20.1 \%$ & 85 & $21.1 \%$ \\
\hline 2016 & 25 & $14.0 \%$ & 60 & $14.9 \%$ \\
\hline 2017 & 29 & $16.2 \%$ & 61 & $15.1 \%$ \\
\hline Total & 179 & $100 \%$ & 403 & $100.00 \%$ \\
\hline
\end{tabular}

While the number of non-surprising articles was noticeably smaller than the surprising articles, that was not all that surprising. Scholars have found that interesting, novel or noteworthy events get reported in the news while routine events are much more likely to not receive attention by the press (Barber $\&$ Odean, 2008; Coleman, 2011).

\section{Measures}

Dependent Variable

Cumulative abnormal return (CAR). The abnormal returns provide the percent change in stock price associated with an event as compared to a market index and informed by risk. The CARs are the abnormal returns cumulated over an event window (McWilliams \& Siegel, 1997). For this study, we used the Wharton Research Data Services (WRDS) Event Study Application.

\section{Independent Variable}

Surprising Actions. The independent variable is a binary variable determined by the structured content analysis of news article found in Factiva (Andrevski et al., 2013; Hughes-Morgan et al., 2018; Hughes-Morgan \& Ferrier, 2017). If the article included one of the keywords describing a surprise and include one of the six types of competitive actions (pricing, product, capacity, service, signaling, and marketing) described by Ferrier and Lee (2002), then it received a value of 1 . If the article explicitly stated that the competitive action was not surprising, then it received a value of 0 . For example, in the article titled "When Google Brainstorms, Online World Shudders; Google Is Considering Using a 'Super Cookie' to Track Browsing Habits," the article stated, "Google is the 800-pound gorilla. So it's no surprise that the scope of its nascent initiative...is being watched warily" (Bussey, 2013). We coded this with a 0 for a surprising action. 


\section{Controls}

Firm size. Consistent with previous research in competitive dynamics, we approximated firm size as the $\log$ of the total number of employees (Andrevski et al., 2014), as firm size has been an important aspect in determining a firm's competition.

Past performance. We controlled for past performance consistent with almost all prior research in competitive dynamics as past performance has been shown to be a predictor of the frequency and type of competitive action as poor performance usually motivates the firm to try something different than what they are currently doing. (Andrevski et al., 2013; W. J. Ferrier, 2001; Margaret Hughes-Morgan \& Ferrier, 2017). We measured past performance as return on assets for the previous year.

Year. We controlled for the year of the action by including a dummy variable for the calendar year that the action occurred.

Actors. In order for a firm to be coded as an actor, the firm needed to be named in the article, and it executed a competitive action. For example, "Microsoft introduced the Surface tablet line last year, a surprise move into hardware" (Clark, 2013). In this example, Microsoft is the actor.

Actee. In order for a firm to be coded as an actee, it met one of the following two criteria: First, the firm was simply named in the article as a competitor of the actor. For example, "But a more painful and unexpected sting came [to Expedia] last month from an old ally, TripAdvisor, the former subsidiary" (FitzGerald, 2013). In this case, Expedia would be the actee as the entire article was about Expedia. Second, if no actee firm or firms were explicitly mentioned in the article, then we used several criteria to select the actees. First, we searched for instances of the acting firm publicly naming its closest competitors. Second, we looked at the U.S. publicly traded firms in the same industry and selected competitors that had similar resources and markets to the originator of the action as scholars state that these are the most likely firms that the competitive action is directed (Miller \& Chen, 1996; Porac \& Thomas, 1990). Third, we looked for competitors that competed in similar markets (Chen \& Miller, 2012). We used the WRDS Computstat - Capital IQ function to determine the actees with similar market capitalization to the actors, as well as a variety of financial websites in an attempt to triangulate the data.

While previous research on competitive dynamics has focused on the action-reaction dyad level of attention (Ferrier \& Lee, 2002; Chen et al., 1992; Smith et al., 1991), certain actions by firms had clear repercussions for more than one competitor (Miller \& Chen, 2013; Smith, Grimm, \& Gannon, 1992). In these cases, more than one competitor were included as actees in the sample. For example, "Chrysler's decision to drop its subsidies request was a surprise" (Rogers \& Vieira, 2014). In this case, Chrysler was coded as the actor. Both Ford and GM were included as the actees.

Industry Dummies. We controlled for the industry of the including dummy variables for the two and three-digit SIC codes (Hendricks \& Singhal, 2003) in order to control for the relationship between industry performance and rivalry (D’Aveni, Dagnino, \& Smith, 2010).

We used the event study methodology approach suggested by McWilliams and Siegel (1997) to measure the abnormal stock price returns associated with a competitive action for firms publicly traded on U.S. stock markets to test hypotheses $1 \mathrm{a}$ and $1 \mathrm{~b}$. Event studies provide a rigorous approach to estimate the stock market's reaction to events while adjusting for market-wide and industry influences on stock prices (Ferrier \& Lee, 2002; Hughes-Morgan \& Ferrier, 2017; MacKinlay, 1997). Our study used only firms publicly traded on the U.S. stock markets reduces the error that could occur due to different cultures experiencing the concept of surprise, as well as various legal environments that influence firms (Chen \& Miller, 2012; Coleman, 2011). See Appendix A for a detailed description of the methodology.

\section{RESULTS}

Table 3 provides the descriptive statistics of the variables in the analysis. The variable Surprising Action has a mean value of 0.74 . The interpretation of this value is that $74 \%$ of the competitive actions (183) were coded as surprising competitive actions versus the $26 \%$ (63) non-surprising actions. A list of the firms, the event dates, the category of competitive actions, the CARs, and the material effects of the competitive actions is available from the author upon request. 
TABLE 3

DESCRIPTIVE STATISTICS AND CORRELATIONS

\begin{tabular}{|c|c|c|c|c|c|c|c|c|c|c|c|c|}
\hline Variables & $\underline{\mathrm{n}}$ & Mean & $\underline{\text { Min }}$ & $\underline{\text { Max }}$ & Std. Dev. & 1 & 2 & 3 & 4 & 5 & 6 & 7 \\
\hline 1. CAR Actors Surprising Action & 72 & 0.01964 & -0.07943 & 0.22095 & 0.05862 & 1.00 & & & & & & \\
\hline 2. CAR Actees Surpring Action & 111 & -0.01379 & -0.30989 & 0.20911 & 0.07396 & 0.00 & 1.00 & & & & & \\
\hline 3. CAR Actors Non-Surprising Action & 31 & 0.00455 & -0.10312 & 0.21301 & 0.06602 & 0.00 & 0.00 & 1.00 & & & & \\
\hline 4. CAR Actees Non-Surprising Action & 32 & -0.0028 & -0.16509 & 0.14799 & 0.05714 & 0.00 & 0.00 & 0.00 & 1.00 & & & \\
\hline 5. Surprising Action & 246 & 0.7439 & 0 & 1 & 0.43737 & 0.00 & 0.00 & 0.00 & 0.00 & 1.00 & & \\
\hline 6. Log Employees & 246 & 4.05 & -0.71949 & 7.74066 & 1.51355 & -0.04 & -0.13 & 0.09 & 0.17 & $-0.23 *$ & 1.00 & \\
\hline 7. Past Performance & 246 & 0.098 & -0.36603 & 0.50433 & 0.10489 & -0.14 & -0.12 & -0.11 & 0.06 & -0.07 & 0.05 & 1.00 \\
\hline
\end{tabular}

${ }^{*}, * * * * *$ indicate statistical significance at the $0.01,0.05$, and 0.1 level respectively

Hypothesis 1 a proposing that a surprise as a result of a competitor's action would have a negative impact on a firm's abnormal return was supported. Table 4 presents the daily abnormal returns for the actees over the event period. For this analysis, only the actees in the articles describing a surprising action were used. These were the firms that were surprised by a competitor's action. We dropped 48 firms from our analysis because these firms were either missing returns during the event period or did not have a minimum of 40 return observations in the estimation period. Therefore, our event study results were based on 111 firms.

The mean cumulative abnormal return on day 0 , the day of the event, was $-1.28 \%(\mathrm{p}<0.0001)$ with an overall mean CAR for the entire event period of $-1.38 \%(\mathrm{p}=0.0025)$. As figure 2 shows, the mean CAR starts a slight downward trend at day -9 , mean CAR of $-0.01 \%(\mathrm{p}=0.45)$, becomes statistically significant at the 0.05 level at day -5 , mean CAR of $-0.79 \%(\mathrm{p}=0.0001)$ and remains significant through day 5. It also remains negative through the event period. This suggests that there was leakage of information prior to the event and the market reacted to a competitive action before it occurred (Barber \& Odean, 2008; Hughes-Morgan \& Ferrier, 2017). The -1.28\% CAR for the surprisees on the day of the event represents an average material effect of a negative $\$ 4.1$ billion loss in market capitalization.

FIGURE 2

ACTEES MEAN CAR OVER EVENT WINDOW (SURPRISING ACTION)

\section{Cumulative Abnormal Return: Mean \& 95\% Confidence Limits}

There are 111 events in total with non-missing returns.

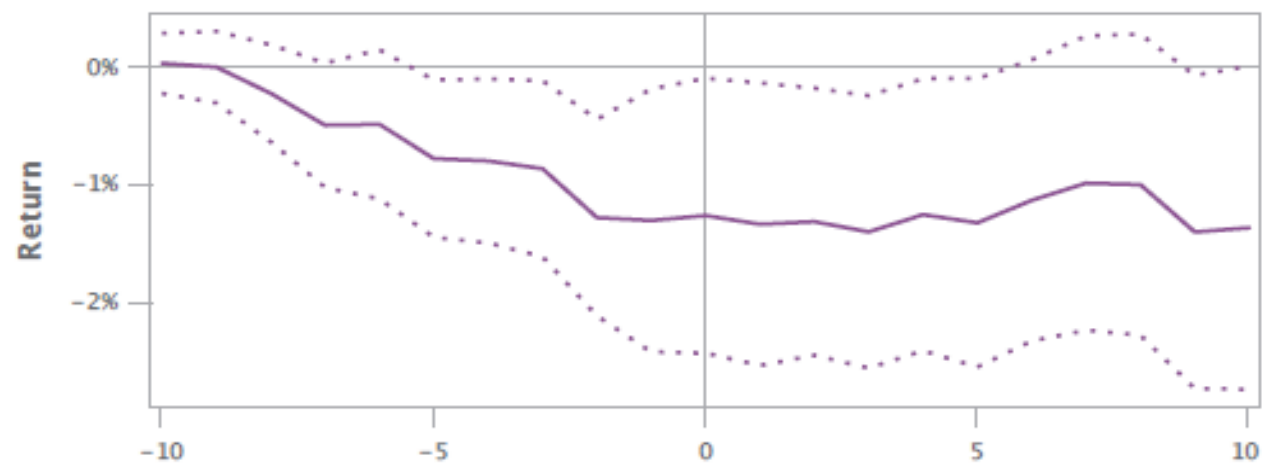

Day Relative to Event

-.'Mean - 1.96SE - Mean -.. Mean + 1.96SE

Hypothesis $1 \mathrm{~b}$ proposing that a surprising action on a competitor would have a positive impact on a firm's abnormal return was supported. Table 4 presents the daily abnormal returns for the actors over the 
event period. For this analysis, only the actors in the articles describing a surprising action were used. These were the firms that were conducted a surprising action. We dropped 58 firms from our analysis because these firms were either missing returns during the event period or did not have a minimum of 40 return observations in the estimation period. Therefore, out event study analysis was based on 72 firms.

\section{FIGURE 3}

\section{ACTORS MEAN CAR OVER EVENT WINDOW (SURPRISING ACTION)}

\section{Cumulative Abnormal Return: Mean \& 95\% Confidence Limits}

There are 72 events in total with non-missing returns.

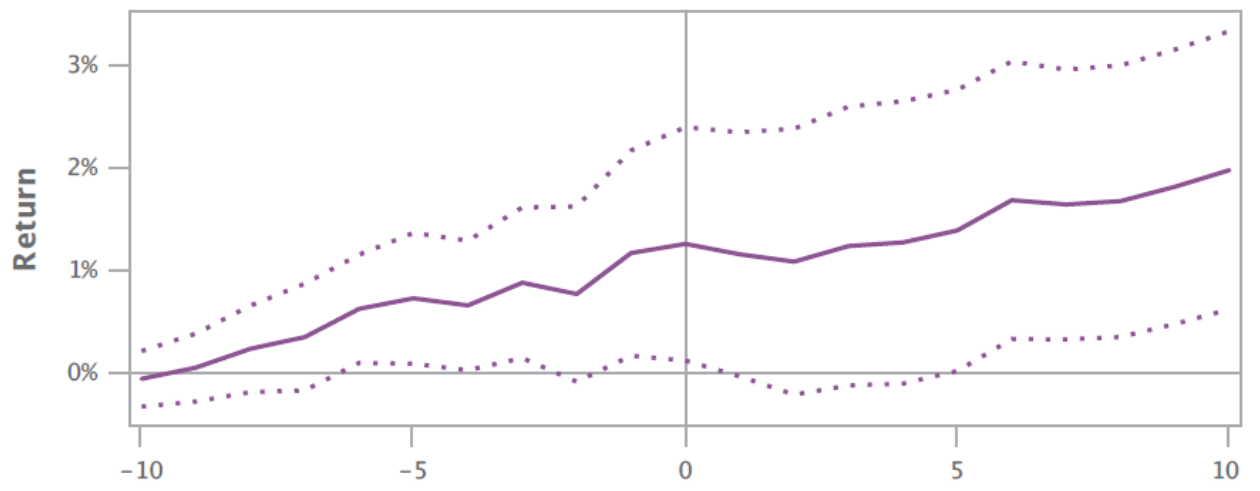

Day Relative to Event

$\because$ Mean - 1.96SE - Mean $\because$ Mean + 1.96SE

The mean cumulative abnormal return on day 0 , the day of the event, is $1.25 \%(\mathrm{p}=0.041)$ with an overall mean CAR for the entire event period of $2.87 \%(\mathrm{p}=0.0026)$. As figure 3 shows, the mean CAR had an overall upward trend over the event period. Similar to hypothesis $1 \mathrm{a}$, this suggests that there was leakage of information prior to the event and the market reacted to the competitive action before it occurred (Barber \& Odean, 2008; Hughes-Morgan \& Ferrier, 2017). The 1.25\% CAR for the surprisors on the day of the event represents an average material effect of $\$ 2.9$ billion. 
TABLE 4

DAILY MEAN CAR FOR ACTORS AND ACTEES (SURPRISING ACTION)

\begin{tabular}{|c|c|c|c|c|}
\hline Day & $\begin{array}{c}\text { Mean CAR } \\
\text { Actors }\end{array}$ & $\begin{array}{c}\text { Test Statistic } \\
\text { (Patell's Z) }\end{array}$ & $\begin{array}{c}\text { Mean CAR } \\
\text { Actees }\end{array}$ & $\begin{array}{c}\text { Test Statistic } \\
\text { (Patell's Z) }\end{array}$ \\
\hline-10 & -0.0007 & 0.3051 & 0.0002 & 0.3477 \\
\hline-9 & 0.0004 & 0.1813 & -0.0001 & -0.1119 \\
\hline-8 & 0.0023 & 1.0212 & -0.0023 & -1.6514 \\
\hline-7 & 0.0034 & 0.1670 & -0.0051 & -1.4472 \\
\hline-6 & 0.0062 & $2.0063^{* *}$ & -0.0050 & 0.2788 \\
\hline-5 & 0.0072 & $0.703^{* *}$ & -0.0079 & $-2.5211^{* *}$ \\
\hline-4 & 0.0065 & $-0.0082^{* *}$ & -0.0081 & $-0.3769^{* *}$ \\
\hline-3 & 0.0087 & $1.4817^{* *}$ & -0.0088 & $-0.4611^{* *}$ \\
\hline-2 & 0.0076 & -1.5070 & -0.0129 & $-3.9603 * *$ \\
\hline-1 & 0.0116 & $1.7569 * *$ & -0.0132 & $-1.5475^{* *}$ \\
\hline 0 & 0.0125 & $0.8486^{* *}$ & -0.0128 & $-1.2107^{* *}$ \\
\hline 1 & 0.0115 & -0.8880 & -0.0135 & $-0.786^{* *}$ \\
\hline 2 & 0.0107 & -0.7098 & -0.0133 & $-0.0482^{* *}$ \\
\hline 3 & 0.0123 & -0.0819 & -0.0141 & $-0.7647^{* *}$ \\
\hline 4 & 0.0126 & -0.0525 & -0.0127 & $1.2782^{* *}$ \\
\hline 5 & 0.0138 & $0.08339^{* *}$ & -0.0134 & $-0.6355^{* *}$ \\
\hline 6 & 0.0167 & $0.1663 * *$ & -0.0115 & 2.053 \\
\hline 7 & 0.0163 & $-0.625^{* *}$ & -0.0100 & 0.8449 \\
\hline 8 & 0.0166 & $-0.2525^{* *}$ & -0.0101 & 0.0868 \\
\hline 9 & 0.0180 & $0.4827^{* *}$ & -0.0142 & $-2.7396^{* *}$ \\
\hline 10 & 0.0196 & $0.4347^{* *}$ & -0.0138 & 0.2372 \\
\hline
\end{tabular}

Hypothesis $2 a$ proposing that firms conducting surprising competitive actions have greater, positive abnormal returns than firms conducting non-surprising competitive actions was supported. As reported in Model 1 of Table 5, the coefficient representing the influence of a surprising action on a firm's CAR is positive and significant $(\mathrm{b}=0.02469, \mathrm{p}=0.0358)$, representing a material effect of $\$ 4.2$ billion.

Hypothesis $2 b$ proposing that firms that are surprised by competitive actions will have greater, negative abnormal returns than firms that are not surprised by competitive actions was supported. As reported in Model 2 of Table 5, the coefficient representing the influence of a surprising action was negative and significant $(b=-0.02652, p=0.0321)$, representing a material effect of $-\$ 4.7$ billion.

\section{Robustness Checks}

In order to ensure that the results were not determined by the choice of the model, we ran the data using a market-adjusted model. The market adjusted model uses the market return as the benchmark. The market-adjusted model for the actees in the articles describing a surprising action had a CAR of $-0.84 \%$ $(\mathrm{p}=0.078)$ on day zero. This result is slightly lower than the market model of $-1.28 \%$. However, it was consistent with the results for H1a. The market-adjusted model for the actors in the articles describing a surprising action had a CAR of $1.06 \%(\mathrm{p}=0.103)$. This CAR was slightly lower compared to the market CAR of $1.25 \%$ at day zero. However, it was consistent with the results for H1b. 


\section{RESULTS OF REGRESSION ANALYSIS}

\begin{tabular}{lrrrr} 
& \multicolumn{4}{c}{ Dependent Variable: CAR } \\
\cline { 2 - 5 } Variable & Model 1(Actors) & \multicolumn{2}{c}{ Model 2 (Actees) } \\
\hline Intercept & Coeft & Std error & Coeft & Std error \\
Surprising Action & 0.00451 & 0.01962 & 0.02153 & 0.01962 \\
Log Employees & $0.02469^{* *}$ & 0.0116 & $-0.02652^{* *}$ & 0.01225 \\
Past Performance & -0.00041 & 0.00379 & -0.00225 & 0.00321 \\
Industry Dummies & -0.08814 & 0.07247 & -0.06534 & 0.04191 \\
N & Included & & Included & \\
F Stat & 103 & & 143 & \\
R Squared & $2.18^{* * *}$ & & $2.15^{* * *}$ & \\
\hline
\end{tabular}

$*, * *, * * *$ indicate statistical significance at the $0.01,0.05$, and 0.1 level respectively

\section{DISCUSSION}

Scholars researching competitive dynamics have provided considerable evidence that the type of competitive action impacts firm performance (Andrevski et al., 2016; Ferrier \& Lee, 2002; HughesMorgan \& Ferrier, 2017). We motivated our study with the observation that scholars and practitioners have a lack of agreement on the extent of resources that should be dedicated to anticipating a competitor's action (Montgomery et al., 2005; Powell \& Allgaier, 1998; Steenkamp et al., 2005). We theorized that surprises on a firm in the context of a competitor's action would produce a negative financial impact to the receiving firm in the form of an abnormal return and an immediate positive financial impact for the firm conducting the action. We asked a strategically relevant question of, In the context of competitor dynamics, how do surprising actions by a competitor impact the abnormal returns of the actor and actee firms?

We found firms that are surprised by a competitor's actions have a negative impact on their stock prices that begins approximately eight days prior to the event occurring (Figure 2). We also found that firms that conduct the surprising action have a positive impact on their stock prices that also begins approximately nine days before the event (Figure 3). We attribute this early impact to the leakage of information through a variety of sources that can occur as large firms conduct competitive actions (Barber \& Odean, 2008; Hughes-Morgan \& Ferrier, 2017), not from the impact of a published article about an event that draws investors' attention since the abnormal returns began prior to publication of any articles about the firms (Barber \& Odean, 2008). While not part of our hypothesis, figures two and three show that the impacts of the surprising competitive action remain significant through at least nine trading days after the event. This may indicate that surprising actions may change the dynamic of the competitive relationship as the impact of news events does not last more than a day or two unless the event signals a true change to the dynamic of the relationship (Coleman, 2011).

\section{CONTRIBUTIONS}

Our contribution informs competitive dynamics research by developing a deeper understanding of the relationship between a surprising competitive action and firm performance. We accomplished this by focusing our theoretical and empirical efforts at the level of a firm in the context of competitive dynamics. By adopting an Event System Theory lens, this study demonstrates that there are negative financial implications for firms that are surprised competitor's actions and positive impacts for firms conducting 
surprising actions. For example, in 2015 when Microsoft conducted a surprising expansion deeper into hardware, including their first laptop with a detachable keyboard, Apple experienced a $-4.1 \%$ abnormal return, reducing the value of the firm by $\$ 25$ billion while Microsoft experienced a $5.5 \%$ abnormal return, increasing the value of the firm by $\$ 19.6$ billion (Ovide, 2015).

The findings of our study situate it in the stream of research in competitive dynamics concerned with the financial impact of competitive actions (Ferrier \& Lee, 2002; Hughes-Morgan et al., 2018). As the primary reason for firms in competitive settings to conduct actions is to gain an advantage (Chen \& Miller, 2012; Smith et al., 1997), our study opens up new opportunities for scholars to incorporate elements of EST in competitive dynamics research. Our study suggests that by conceptualizing a surprising action as a novel event, it will contribute to new theoretical perspectives on the specific types of competitive actions.

\section{Managerial Implications}

The analysis of value loss by shareholders due to competitor's actions due to surprise is an important implication for managers because scholars have shown that not all managers are convinced that anticipating potential surprises by competitors is worth the costs (Montgomery et al., 2005; Steenkamp et al., 2005; Wright et al., 2009) or particularly effective (Powell \& Allgaier, 1998). The analysis indicates that there is a negative financial impact to getting surprised by a competitor. In addition, there is a positive impact on firms that conduct surprising action that potentially lasts long term. This analyses could provide the justification for firms to invest in a competitive intelligence function that provides firms with the ability to learn about their external environment and apply those lessons learned to increase the quality and speed of decision-making in the firm (Prescott, 2014). The analysis could also motivate managers to develop actions that are likely to surprise their competitors.

\section{Limitations and Future Research Directions}

This study has several limitations that can be addressed in future studies. First, we based the operationalization of the construct of surprise on either second or third-party information based on the reporting in the Wall Street Journal or the Wall Street Journal online. While these articles express the concept of surprise, unless they had a direct quote from a decision-maker in the organization expressively stating that the firm was surprised, it is possible that the surprise occurred only to the analyst or reporter. Thus, a future research opportunity is to use a mixed-methods approach involving semi-structured interviews of competitive intelligence professions or senior managers in firms to triangulate the data to confirm that a surprise occurred. This approach will enable a confirmation or corroboration of the analysis conducted in this study (Venkatesh, Brown, \& Bala, 2013).

In addition, our analysis suggests that the impacts of the surprising action are not short-lived, but can persist over time. Previous scholars have suggested that most firms have a small abnormal return after news events and the impact does not last more than a day or two unless the event signals a true change to the dynamic of the relationship (Coleman, 2011). Future scholars could conduct an in-depth analysis of each surprising action to determine if these actions fundamentally altered the competitive dynamic relationship between the firms.

Another limitation is that the actees that were not expressly identified in the article were identified through a variety of sources. Previous scholars have articulated the ambiguity associated with determining which firms the competitive actions were directed against (Tsai, Su, \& Chen, 2011). While we have attempted to determine the correct competitors accurately, we recognize that only the acting firms know which competitor they directed their actions. Since managers and researchers can differ significantly in the determination of the firm's competitors (Porac \& Thomas, 1990), conducting interviews with the firms conducting the competitive actions will allow future researchers to provide a more fine-grain analysis of surprising actions.

Further, our study suggests that the market reacts to surprising competitive actions prior to the action occurring. This leakage of information provides an opportunity for future scholars to study the mechanism and timing of this private information transfer. Understanding this mechanism has merits for 
both actors and the actees. The actors have a motivation to minimize the leakage in order to maintain the surprise, and the actees would prefer to learn about the upcoming action as early as possible to minimize the damage as well as prepare a competitive response.

\section{CONCLUSION}

This study emphasized the importance of understanding the impact of surprising competitive actions. An expectation mechanism explains the market reaction to the surprising actions on both the firms conducting the action or the firms at which the action was directed. Establishing and testing theory that associates surprise and the abnormal returns of the firm provides scholars and practitioners a theoretical rationale for committing limited resources towards understanding and mitigating the effects of surprising competitor's actions, as well as developing methods to surprise competitors.

\section{DISCLAIMER}

The views expressed are those of the author and do not necessarily reflect the official policy or position of the Department of the Army, Department of Defense, or the U.S. Government.

\section{REFERENCES}

Ackerman, A. (2013, August 11). Money Funds Embrace a Rule They Shunned; Banks and Other Money-Fund Sponsors Back Shift to Float. The Wall Street Journal Online.

Agrawal, J., \& Kamakura, W. (1995). The Economic Worth of Celebrity Endorsers: An Event Study Analysis. Journal of Marketing, 59(3), 56-62.

Allen, P. M., Varga, L., \& Strathern, M. (2010). The evolutionary complexity of social and economic systems: The inevitability of uncertainty and surprise. Risk Management, 12(1), 9-30.

Andrevski, G., Brass, D. J., \& Ferrier, W. J. (2013). Alliance Portfolio Configurations and Competitive Action Frequency. Journal of Management, 42(4), 811-837.

Andrevski, G., Richard, O. C., Shaw, J. D., \& Ferrier, W. J. (2014). Racial Diversity and Firm Performance: The Mediating Role of Competitive Intensity. Journal of Management, 40(3), 820 844.

Barber, B., \& Odean, T. (2008). All That Glitters: The Effect of Attention and News on the Buying Behavior of Individual and Institutional Investors. The Review of Financial Studies, 21(2), 785818.

Barney, J. B. (1986). Strategic Factor Markets: Expectations, Luck, and Business Strategy. Management Science, 32(10), 1231-1241.

Barto, A., Mirolli, M., \& Baldassarre, G. (2013). Novelty or Surprise? Frontiers in Psychology, 4, 1-15.

Baum, J. A. C., \& Korn, H. J. (1996). Competitive Dynamics of Interfirm Rivalry. Academy of Management Journal, 39(2), 255-291.

Bechky, B. A., \& Okhuysen, G. A. (2011). EXPECTING THE UNEXPECTED? HOW SWAT OFFICERS AND FILM CREWS HANDLE SURPRISES. Academy of Management Journal, 54(2), 239-261.

Bundy, J., Pfarrer, M. D., Short, C. E., \& Coombs, T. (2017). Crises and Crisis Management: Integration, Interpretation, and Research Development. Journal of Management, 43(6), 1661-1692.

Burt, G. (2007). Why are we surprised at surprises? Integrating disruption theory and system analysis with the scenario methodology to help identify disruptions and discontinuities. Technological Forecasting and Social Change, 74(6), 731-749.

Chauvin, K. W., \& Guthrie, J. P. (1994). Labor market reputation and the value of the firm. Managerial and Decision Economics, 15(6), 543-552.

Chen, M., \& Miller, D. (1994). Competitive Attack, Retaliation and Performance: An ExpectancyValence Framework. Strategic Management Journal, 15(2), 85-102. 
Chen, M., \& Miller, D. (2012). Competitive Dynamics: Themes, Trends, and a Prospective Research Platform. Academy of Management Annals, 6(434), 1-83.

Chen, M., \& Miller, D. (2015). RECONCEPTUALIZING COMPETITIVE DYNAMICS: A MULTIDIMENSIONAL FRAMEWORK. Strategic Management Journal, 36, 758-775.

Coleman, L. (2011). An Exploratory analysis of factors influencing initial market response and media reports following shock corporate events. Financial Review, 46(2), 313-336.

Connelly, B. L., Tihanyi, L., Ketchen, D. J., Carnes, C. M., \& Ferrier, W. J. (2017). Competitive repertoire complexity: Governance antecedents and performance outcomes. Strategic Management Journal, 38(5), 1151-1173.

Cornelissen, J. P. (2012). Sensemaking Under Pressure : The Influence of Professional Roles and Social Accountability on the Creation of Sense. Organization Science, 23(1), 118-137.

Cunha, M. P., Clegg, S. R., \& Kamoche, K. (2006). Surprises in Management and Organization: Concept, Sources and a Typology. British Journal of Management, 17(4), 317-329.

D’Aveni, R. A., Dagnino, G. B., \& Smith, K. G. (2010). The age of temporary advantage. Strategic Management Journal, 31(13), 1371-1385.

Derfus, P. J., Maggitti, P. G., Grimm, C. M., \& Smith, K. G. (2008). The Red Queen Effect: Competitive Actions and Firm Performance. Academy of Management Journal, 51(1), 61-80.

Elliot, A. J., \& Devine, P. G. (1994). On the motivational nature of cognitive dissonance. Journal of Personality and Social Psychology.

Feldman, M. S., \& Pentland, B. T. (2003). Reconceptualizing and Change. Administrative Science Quarterly, 48(March), 94-118.

Ferrier, W. J. (2001). Navigating the competitive landscape: The drivers and consequences of competitive aggressiveness. Academy of Management Journal, 44(4).

Ferrier, W. J., \& Lee, H. (2002). Strategic aggressiveness, variation, and surprise: How the sequential pattern of competitive rivalry influences stock market returns. Journal of Managerial Issues, 14(2), 162-180.

Fontaine, J. R., Scherer, K. R., Roesch, E. B., \& Ellsworth, P. C. (2007). The World of Emotions Is Not Two-Dimensional. Psychological Science, 18(12), 1050-1057.

Goins, S., \& Gruca, T. S. (2008). Understanding Competitive and Contagion Effects of Layoff Announcements. Corporate Reputation Review, 11(1), 12-34.

Hendricks, K. B., \& Singhal, V. R. (2003). The effect of supply chain glitches on shareholder wealth. Journal of Operations Management, 21(5), 501-522.

Hillmann, J., Duchek, S., Meyr, J., \& Guenther, E. (2018). Educating Future Managers for Developing Resilient Organizations: The Role of Scenario Planning. Journal of Management Education, 42(4), 461-495.

Hughes-Morgan, M., \& Ferrier, W. J. (2017). 'Short Interest Pressure' and Competitive Behaviour. British Journal of Management, 28(1), 120-134.

Hughes-Morgan, M., Ferrier, W. J., \& Morgan, F. (2018). Clear Signals or Ambiguity? How LongBuyers and Short-Sellers React Differently to Competitive Actions. Journal of Managerial Issues, 1(1), 63-81.

Kaplan, S. (2012). Savoring surprise: The leadership learning opportunity. Strategy \& Leadership, 40(6), $46-50$.

Kasznik, R., \& Lev, B. (1995). To Warn or Not to Warn: Management Disclosures in the Face of an Earnings Surprise. The Accounting Review, 70(1), 113-134.

Kay, A. C., Whitson, J. A., Gaucher, D., \& Galinsky, A. D. . (2009). Compensatory control: Achieving order through the mind, our institutions, and the heavens. Current Directions in Psychological Science, 18(5), 264-268.

Lee, H., Smith, K. G., Grimm, C. M., \& Schomburg, A. (2000). Timing, order and durability of new product advantages with imitation. Strategic Management Journal, 21(1), 23-30.

MacKinlay, C. A. (1997). Finance event studies in Economics and Finance. Journal of Economic Literature, 35(1), 13-39. 
Manski, C. F. (2004). Measuring Expectations. Econometrica, 72(5), 1329-1376.

Marsland, S. (2002). Novelty Detection in Learning Systems. Neural Computing Surveys, 3, 1-39.

Más-Ruiz, F. J., Nicolau-Gonzálbez, J. L., \& Ruiz-Moreno, F. (2005). Asymmetric rivalry between strategic groups: Response, speed of response and ex ante vs. ex post competitive interaction in the spanish bank deposit market. Strategic Management Journal, 26(8), 713-745.

McNamara, G. M., Haleblian, J., \& Dykes, B. J. (2008). The performance implications of participating in an acquisition wave: Early mover advantages, bandwagon effects, and the moderating influence of industry characteristics and acquirer tactics. Academy of Management Journal, 51(1), 113130.

McWilliams, A., \& Siegel, D. (1997). Event Studies in Management Research: Theoretical and Empirical Issues. Academy of Management Journal, 40(3), 626-657.

Miller, D., \& Chen, M. (1994). Sources and Consequences of Competitive Inertia: A Study of the U.S. Airline Industry. Administrative Science Quarterly, 39(1), 1-23.

Miller, D., \& Chen, M. (1996). The Simplicity of Competitive Repertoires: An Empirical Analysis. Strategic Management Journal, 17, 419-439.

Montgomery, D. B., Moore, M. C., \& Urbany, J. E. (2005). Reasoning about Competitive Reactions: Evidence from Executives. Marketing Science, 24(1), 138-149.

Morgeson, F. P. (2005). The External Leadership of Self-Managing Teams: Intervening in the Context of Novel and Disruptive Events. Journal of Applied Psychology, 90(3), 497-508.

Morgeson, F. P., Mitchell, T. R., \& Liu, D. (2015). Event system theory: An event-oriented approach to the organizational sciences. Academy of Management Review, 40(4), 515-537.

Muth, J. F. (1961). Rational Expectations and the Theory of Price Movements. Econometrica, 29(3), 315335.

Nag, R., Hambrick, D., \& Chen, M.-J. (2007). What is Strategic Management, Really? Strategic Management Journal, 28, 935-955.

Neugarten, M. L. (2006). Foresight-Are we looking in the right direction? Futures, 38(8), 894-907.

Patriotta, G., \& Gruber, D. A. . (2015). Newsmaking and Sensemaking: Navigating Temporal Transitions Between Planned and Unexpected Events. Organization Science, 26(6), 1574-1592.

Pearson, C. M., \& Clair, J. A. (1998). Reframing crisis management. The Academy of Management Review, 23(1), 59-76.

Poppo, L., \& Schepker, D. (2012). The repair of public trust following controllable or uncontrollable organizational failures: A conceptual framework. In Public Trust in Business (pp. 326-360).

Porac, J. F., \& Thomas, H. (1990). Taxonomic Mental Models in Competitor Definition. Academy of Management Review, 15(2), 224-240.

Powell, T., \& Allgaier, C. (1998). Enhancing sales and marketing effectiveness through competitive intelligence. Competitive Intelligence Review, 9(4), 29-41.

Prescott, J. E. (2014). Intelligence Studies in Business. In G. Moore (Ed.), The Encyclopedia of U.S. Intelligence. Auerbach Publications.

Proulx, T., Inzlicht, M., \& Harmon-Jones, E. (2012). Understanding all inconsistency compensation as a palliative response to violated expectations. Trends in Cognitive Sciences, 16(5), 285-291.

Ranganath, C., \& Rainer, G. (2003). Cognitive neuroscience: Neural mechanisms for detecting and remembering novel events. Neuroscience, 4(3), 193-202.

Russel, J. A. (1980). A Circumplex Model of Affect. Journal of Personality and Social Psychology, 39(6), 1161-1178.

Rutjens, B. T., Van Harreveld, F., Van Der Pligt, J., Kreemers, L. M., \& Noordewier, M. K. (2013). Steps, stages, and structure: Finding compensatory order in scientific theories. Journal of Experimental Psychology: General, 142(2), 313-318.

Smith, K. G., Grimm, C. M., \& Gannon, M. J. (1992). Dynamics of competitive strategy. Dynamics of competitive strategy. Thousand Oaks, CA, US: Sage Publications, Inc.

Smith, K. G., Grimm, C. M., Wally, S., \& Young, G. (1997). Strategic Groups and Rivalrous Firm Behavior: Towards a Reconciliation. Strategic Management Journal, 18(2), 149-157. 
Stambaugh, J., Lumpkin, G. T., Brigham, K., \& Cogliser, C. (2009). What Makes Some Firms More Competitively Aggressive Than Others? Evidence From the Banking Industry. Academy of Management Annual Meeting Proceedings, 8(1), 1-6.

Steenkamp, J., Nijs, V. R., Hanssens, D. M., \& Dekimpe, M. G. (2005). Competitive Reactions Promotion to Advertising and Attacks. Marketing Science, 24(1), 35-54.

Summerfield, C., \& Egner, T. (2009). Expectation (and attention) in visual cognition. Trends in Cognitive Sciences, 13(9), 403-409.

Topolinski, S., \& Strack, F. (2015). Corrugator activity confirms immediate negative affect in surprise. Frontiers in Psychology, 6, 1-8.

Tsai, W., Su, K., \& Chen, M. (2011). Seeing Through the Eyes of a Rival: Competitor Acumen Based on Rival-Centric Perceptions. Academy of Management Journal, 54(4), 761-778.

Valenzuela, A., Mellers, B., \& Strebel, J. (2010). Pleasurable Surprises: A Cross-Cultural Study of Consumer Responses to Unexpected Incentives. Journal of Consumer Research, 36(5), 792-805.

Venkatesh, V., Brown, S. A., \& Bala, H. (2013). Bridging the Qualitative-Quantitative Divide: Guidelines for Conducting Mixed Methods Research in Information Systems. MIS Quarterly, 37(1), 21-54.

Vergin, R. C., \& Qoronfleh, M. W. (1998). Corporate reputation and the stock market. Business Horizons, 41(1), 1-21.

Wright, S., Eid, E. R., \& Fleisher, C. S. (2009). Competitive intelligence in practice: empirical evidence from the UK retail banking sector. Journal of Marketing Management, 25(9-10), 941-964.

Young, G., Smith, K. G., \& Grimm, C. M. (1996). "Austrian” and Industrial Organization Perspectives on Firm-level Competitive Activity and Performance. Organization Science, 7(3), 243-254.

Zantout, Z., \& Chaganti, R. (1996). New Product Introductions, Shareholders' Wealth, and First-Mover Advantages. Journal of Financial and Strategic Decisions, 9(3), 49-61. 


\section{APPENDIX A}

Consistent with previous research (Hendricks \& Singhal, 2003) we used the market model as it controls for a key factor in explaining stock returns, the systematic risk of the stock. The market model uses abnormal returns defined according to the Capital Asset Pricing Model (CAPM):

$R_{j t}=\alpha_{j}+\beta_{j} R_{m t}+\varepsilon_{j t}$

$R_{j t}$ is the return of the stock on day $t, \alpha_{j}$ is an estimate of the constant daily return for stock $j, \beta_{j} R_{m t}$ is the portion of the return for the stock $j$ due to market-wide movements, and $\varepsilon_{j t}$ is the error term of the stock that cannot be explained by market movements. The model is then regressed using ordinary least squares regression which provides estimations of $\hat{\alpha}$ and $\widehat{\beta}_{J}$ used in the calculation of abnormal returns in the following formula.

$A R_{j t}=R_{j t}-\left(\hat{\alpha}+\widehat{\beta}_{J} * R_{m t}\right)$

$A R_{j t}$ is the abnormal return for stock $j$ on Day $t$, and it is the difference between the actual return of stock $j$ on Day $t, R_{j t}$, and $\left(\hat{\alpha}+\widehat{\beta}_{J} * R_{m t}\right)$ where $\hat{\alpha}$ is an estimate of the constant daily return for stock $j$. $\widehat{\beta_{J}} * R_{m t}$ is the portion of the return for stock $j$ that is due to market-wide movements.

The test statistic is the widely used Patell's $\mathrm{Z}$ which standardizes the event window abnormal returns by the standard deviation of the estimation period abnormal returns using the following formula:

$t_{\text {Patell }}=\operatorname{mean}\left(S C A R_{j t}\right) / \frac{\sqrt{\sum_{j=1}^{N} \frac{K_{j}-2}{K_{j}-4}}}{N}$

$\mathrm{N}$ is the number of stocks in the sample, $K_{j}$ is the number of non-missing returns in stock $\mathrm{j}$ 's estimation period, and $S C A R_{j t}$ is the standardized cumulative abnormal return of the stock $j$ (WRDS, 2018).

Next, we set the estimation parameters for the event study. We selected 200 days as the length of the period (in trading days) used to estimate the expected return and residual return variance consistent with prior research. Next, we selected the minimum number of non-missing return observations within the estimation window required to produce estimates of expected return as 40 , as estimating two parameters with less than 40 points is not statistically sound (Hendricks \& Singhal, 2003). We also selected a gap of 10 trading days between the end of the estimation window and the beginning of the event window. The gap is to reduce the likelihood that the risk model estimation is affected by the event-induced return variance (WRDS, 2018). Next, we selected the event window start time and the event window end time. According to MacKinlay (1997), it is customary to define an event window that is larger than the specific period of interest. This larger event window allows the examination of the timeframe on either side of the event. As the market receives information from multiple sources, both public and private, it is possible that the market has adjusted to the information before the event becomes public knowledge (Barber \& Odean, 2008). Consistent with previous research (Agrawal \& Kamakura, 1995), we used ten days both before and after the event to analyze the effects of the surprise to account for the possibility that private information leaked (Hughes-Morgan \& Ferrier, 2017) that the competitive action was about to occur.

We used the following regression model to test hypotheses $2 \mathrm{a}$ and $2 \mathrm{~b}$ :

$$
\text { CAR }=\beta_{0}+\beta_{1} \text { Surprise }+\beta_{2} \text { Size }+\beta_{3} \text { PastPerformance }+\beta \text { Industry }+\varepsilon
$$

The model was run for both the Actors, the firms that conducted the action, and the Actees, the firms that were the target of the action. 